\title{
Chronic Hepatitis C as a Risk Factor for Colonic Neoplasia in a Community Setting
}

Poulos J E'*, Ingram B ${ }^{2}$, Milanov $\mathbf{V}^{3}$, Conti $\mathrm{M}^{4}$, Ingram $\mathbf{T}^{\mathbf{5}}$ and Poulos $\mathrm{E}^{\mathbf{6}}$

${ }^{1}$ University of South Florida Morsani College of Medicine, USA

${ }^{2}$ Cape Fear Valley Medical Center, USA

${ }^{3}$ Department of Mathematics and Computer Science, University of Fayetteville State, USA

${ }^{4}$ Campbell University School of Medicine, USA

${ }^{5}$ St. George's University School of Medicine, Grenada

${ }^{6}$ University of Alabama at Birmingham School of

Medicine, USA

*Corresponding author: J ohn E Poulos, University of South Florida Morsani College of Medicine, Fayetteville Gastroenterology Associates, Fayetteville, NC, USA

Received: J anuary 04, 2021; Accepted: February 03, 2021; Published: February 10, 2021

\section{Introduction}

An estimated 3.5 million people have Chronic Hepatitis C (CHC) in the United States [1]. With the current opioid epidemic, the number of people who are injecting drugs in the US. Has substantially increased the incidence of $\mathrm{CHC}$ virus [2]. With an apparent second wave of $\mathrm{CHC}$, it will be important to manage the sequelae of these chronically infected patients and recognize associated comorbidities. $\mathrm{CHC}$ has been shown to increase the risk of hepatocellular carcinoma and has been linked to such malignancies as Non-Hodgkin lymphoma, cholangiocarcinoma, breast, pancreatic, renal, skin/oral, thyroid, and colon cancer [3-6]. Colon cancer is the second leading cause of cancer-related death in men in developed countries and the third most prevalent cause of death from cancer for women [7]. Colorectal Cancer (CRC) screening has been shown to reduce the risk for the development of CRC and prevent the development of more advanced disease $[8,9]$.

The risks for developing colorectal cancer are associated with increasing age, family history, history of adenomas or Inflammatory Bowel Diseases (IBD) and ethnicity. Other possible risk factors include a high fat, low-fiber diet, obesity, smoking, and excessive alcohol use. A possible link between colon cancer and CHC has not been extensively studied. However, previous studies have suggested that patients with $\mathrm{CHC}$ have a higher risk of colonic adenomas and more advanced lesions. Thus, the goal of this study was to determine if patients with $\mathrm{CHC}$ undergoing screening or surveillance colonoscopies in a community setting have an increased risk of colonic neoplasia.

\section{Methods}

This was a retrospective, case-controlled study. The study population consisted of patients with $\mathrm{HCV}$ infection with $\mathrm{HCV}$ RNA $>1,000 \mathrm{IU} / \mathrm{ml}$ undergoing either screening or surveillance colonoscopies from April 2008 to November 2015. The participants of the control group were average risk patients for colorectal cancer undergoing screening colonoscopies during the same time period and were matched with $\mathrm{CHC}$ patients according to age, sex, and race. A total of 370 patients were included in the study with 185 patients in each group respectively. Data from 126 patients was available for surveillance analysis.

The database for this study included colonoscopy, histopathology, age, sex, race, and BMI (calculated using height and weight). Other risk factors that were recorded were diabetes mellitus type 1 or 2 , smoking history, alcohol history, family history, aspirin use, and statin use. Smoking history was defined as any history of smoking that was recorded in the patients charts, regardless of current status. Alcohol history was defined as any current or past alcohol usage. Family history was defined as diagnosed colon cancer in a firstdegree or second-degree relative. Aspirin and statin use were defined as current everyday use of these medications at the time of their last colonoscopy. This data was collected for both the study population and the control population corresponding to the patients most recent colonoscopy.

Each participant had a screening colonoscopy (index colonoscopy) with results recorded along with the year the colonoscopy was performed. Surveillance colonoscopies, defined as any colonoscopy after the index colonoscopy, the number of years since the previous colonoscopy, and the subsequent result were also recorded. For each colonoscopy reported, the total number of polyps were recorded. In addition, the size of the polyps were also recorded based on two categories. The categories were less than $7.5 \mathrm{~mm}$ or greater than or equal to $7.5 \mathrm{~mm}$. The polyps were further subdivided into tubular adenomas and advanced neoplasia. Advanced neoplasia was defined as villous histology, high-grade dysplasia, or adenocarcinoma on pathology.

The main outcomes of the study was the incidence of colorectal adenomas and advanced neoplasia. Collectively they are referred as polyps to form an indicator variable $1 / 0$ (yes/no polyps). Logistic regression was performed on the data. A p-value of $<0.05$ was considered statistically significant. In this instance, a small p-value indicates that the chance of a research group reproducing results that are at least as strong as ours is highly possible. This would support our hypothesis of patients with $\mathrm{CHC}$ having an increased risk of developing colonic neoplasia. Logistic regression analysis was used to describe data and to explain the relationship between the dependent variable (yes/no polyps) and AGE, SEX, BMI, and the following indicator variables (yes/no) SMOKING, STATIN (statin use), DIABET (diabetes mellitus), FAM (family history), ASPIRIN (aspirin, nsaid use), CHC (hepatitis diagnosis) as systematic component was: In the logit model $\mathrm{p}=\mathrm{P}$ (Polyp Present), probability of polyp present is the dependent variable. The estimation method for fitting the model used the R-package glm. 
Table 1: Baseline characteristics of patients undergoing colorectal cancer screening and surveillance in patients with $\mathrm{CHC}$ and controls.

\begin{tabular}{|c|c|c|c|c|c|c|}
\hline & \multicolumn{3}{|c|}{ Screening } & \multicolumn{3}{|c|}{ Surveillance } \\
\hline & controls & $\mathrm{CHC}$ & \multirow{2}{*}{$\mathrm{p}$-value } & controls & $\mathrm{CHC}$ & \multirow{2}{*}{$\mathrm{p}$-value } \\
\hline & $(n=185)$ & $(n=185)$ & & $(n=59)$ & $(n=67)$ & \\
\hline Age & 59.4 & 59.5 & 0.9393 & 61.8 & 62 & 0.8116 \\
\hline Male Sex (\%) & $110(59.4)$ & 109 (58.9) & $>0.99$ & 29 (49.1) & $40(59.7)$ & 0.3136 \\
\hline BMI (\%) & $92(49.7)$ & $68(36.8)$ & $0.0158^{* *}$ & $27(45.8)$ & $19(28.4)$ & $0.0659^{*}$ \\
\hline Smoking (\%) & $88(47.6)$ & $139(74.1)$ & $<0.01^{* *+*}$ & $28(47.5)$ & $44(65.7)$ & $0.0599^{*}$ \\
\hline Statin Use (\%) & 69 (37.3) & $26(14.1)$ & $<0.01^{*+*+}$ & $26(44.1)$ & $10(14.9)$ & $<0.01^{\text {t+x }}$ \\
\hline Diabetes Mellitus (\%) & $47(25.4)$ & $53(28.6)$ & 0.5583 & $12(20.3)$ & $29(43.3)$ & $0.0107^{* *}$ \\
\hline Family History of CRC (\%) & $12(6.5)$ & $25(13.5)$ & $0.0375^{* *}$ & $8(13.6)$ & $12(17.9)$ & 0.6725 \\
\hline Aspirin Use (\%) & $74(40.0)$ & $51(27.6)$ & $0.0156^{* *}$ & $27(45.8)$ & $26(38.8)$ & 0.5429 \\
\hline
\end{tabular}

Significance levels are denoted as: ${ }^{*} 0.05<p<0.10,{ }^{* *} 0.01<p<0.05,{ }^{* * *} p<0.01$

\section{Results}

The screening data consisted of 185 patients with $\mathrm{CHC}$ and 185 non-hepatitis controls. The surveillance group had $67 \mathrm{CHC}$ patients and 59 control group patients. Baseline characteristics of patients assessed are transcribed in (Table 1). The CHC group had a significantly higher number of adenomas detected on screening colonoscopy when compared to the control group ( $70.8 \%$ vs. $44.9 \%$; $\mathrm{p}<0.001$, respectively). The study group also had a significant number of larger polyps, defined as being larger than $7.5 \mathrm{~mm}(31.3 \%$ vs. $18.9 \% ; \mathrm{p}<0.05$, respectively). A trend toward advanced neoplasia was noticed in the CHC group, however, it was not statistically significant ( $8 \%$ vs. $4 \% ; \mathrm{p}<0.15)$ (Table 2). Regression analysis was performed by taking age, sex, BMI, smoking history, statin use, diabetes mellitus, family history, aspirin use, and the hepatitis diagnosis into account. $\mathrm{CHC}$ and male sex were found to be the only independent risk factors for colonic neoplasia on regression analysis. The multivariate odds ratio of having polyps in CHC was $255 \%$ higher than in controls (odds ratio 3.55, 95\% Confidence Interval (CI): 2.15, 5.94) (Table $3)$. In the surveillance data, the total number of patients with adenomas was higher in the CHC group than in controls $(61 \%$ vs. $46 \%, \mathrm{p}<0.12$ ). The $\mathrm{CHC}$ group had a trend of having polyps larger than $0.75 \mathrm{~cm}$ in comparison to controls $(25.3 \%$ vs. $18.6 \%, \mathrm{p}=\mathrm{NS})$ (Table 2). Surveillance data regression analysis revealed $\mathrm{CHC}$ as an independent risk factor for the development of colonic neoplasia. The Table 2: Comparison of colorectal neoplasia in the $\mathrm{CHC}$ group and the control group. odds of having polyps for CHC patients were $228 \%$ higher than in controls (odds ratio 3.28, 95\% CI: 1.37, 8.25) (Table 3).

\section{Discussion}

This study indicates an association between increased numbers of polyps and more advanced neoplasia in patients with $\mathrm{CHC}$ undergoing screening colonoscopy. We also demonstrate a higher rate of colorectal adenomas in surveillance colonoscopies of $\mathrm{CHC}$ patients. This study could have compelling implications for screening and surveillance colonoscopy in patients with CHC. Data was also collected on the established risk factors and protective factors for colorectal neoplasia. Known risk factors associated with colorectal adenomas are age, male sex, obesity, smoking, diabetes mellitus, and family history [10-16]. A healthy lifestyle is strongly associated with lower risk of all stages of colorectal neoplasm [17]. Aspirin and statin use are also associated with decreased incidence of colorectal adenomas [18-20]. In this study, the only determinants for higher risk of adenomatous polyps was male sex and chronic hepatitis C. Obesity and family history were also positive predictors, but did not reach significance in our study. We also found aspirin and statin use to be negative predictors in concordance with other known protective factors in research, but were not significant. Age, smoking, statin use, diabetes, and aspirin use did not appear to confer protection or risk for colonic neoplasia. The relatively small sample size may have impacted the detection of other existing risk factors for adenomatous polyps or

\begin{tabular}{|c|c|c|c|c|c|c|}
\hline & \multicolumn{3}{|c|}{ Screening } & \multicolumn{3}{|c|}{ Surveillance } \\
\hline & $\mathrm{CHC}$ group & Control group & \multirow{3}{*}{$p$-value } & $\mathrm{CHC}$ & Control group & \multirow{3}{*}{$\mathrm{p}$-value } \\
\hline & \multirow[t]{2}{*}{$(n=185)$} & \multirow[t]{2}{*}{$(n=185)$} & & group & $(n=59)$ & \\
\hline & & & & $(n=67)$ & & \\
\hline \multirow{2}{*}{ Adenomas (\%) } & \multirow{2}{*}{$131(70.8)$} & 85 & \multirow{2}{*}{$<0.001$} & 41 & 27 & \multirow{2}{*}{0.016} \\
\hline & & -44.9 & & -61 & -46 & \\
\hline Advanced Neoplasia & 14 & 7 & & \multirow{3}{*}{ * } & \multirow{3}{*}{ * } & \multirow{3}{*}{ * } \\
\hline \multirow[t]{2}{*}{$(\%)$} & & & & & & \\
\hline & -8 & -4 & $<0.15$ & & & \\
\hline Polyps & \multirow{3}{*}{$58(31.3)$} & 37 & \multirow{3}{*}{$<0.05$} & 23 & 16 & \multirow{3}{*}{ NS } \\
\hline$>0.75 \mathrm{~cm}$ & & -18.9 & & -25.3 & -18.6 & \\
\hline$(\%)$ & & & & & & \\
\hline
\end{tabular}

${ }^{*}$ Due to the small number of advanced neoplasia polyps observed (1 in control, 2 in $\mathrm{CHC}$ ) in the surveillance groups, a meaningful statistical test could not be performed. 
Table 3: Subgroup analysis for the presence of polyps in the $\mathrm{CHC}$ and control groups undergoing screening and surveillance colonoscopy.

\begin{tabular}{|c|c|c|c|c|c|c|}
\hline \multirow[b]{2}{*}{ Logistic Regression } & \multicolumn{3}{|c|}{ Screening } & \multicolumn{3}{|c|}{ Surveillance } \\
\hline & Coefficient & p-value & Multivariate OR $(95 \% \mathrm{CI})$ & Coefficient & $\mathrm{p}$-value & Multivariate OR $(95 \% \mathrm{Cl})$ \\
\hline Age & -0.011 & 0.54 & $0.98(0.95-1.03)$ & 0.012 & 0.72 & $1.01(0.95-1.08)$ \\
\hline Male Sex & $0.970^{* * *}$ & 0.001 & $2.63(1.65-4.25)$ & 0.215 & 0.59 & $1.24(0.56-2.78)$ \\
\hline BMI & 0.022 & 0.22 & $1.02(0.99-1.06)$ & 0.062 & 0.11 & $1.06(0.99-1.15)$ \\
\hline Smoking & -0.376 & 0.15 & $0.67(0.41-1.12)$ & -0.336 & 0.41 & $0.71(0.31-1.60)$ \\
\hline Statin Use & -0.131 & 0.65 & $0.87(0.50-1.56)$ & -0.464 & 0.32 & $0.63(0.25-1.58)$ \\
\hline Diabetes Mellitus & -0.31 & 0.26 & $0.73(0.43-1.26)$ & -0.743 & 0.11 & $0.48(0.18-1.19)$ \\
\hline Family History of CRC & 0.466 & 0.27 & $1.59(0.71-3.86$ & 0.575 & 0.21 & $1.78(0.60-5.85$ \\
\hline Aspirin Use & -0.13 & 0.62 & $0.88(0.52-1.48)$ & -0.207 & 0.62 & $0.81(0.35-1.89)$ \\
\hline CHC Positive & $1.267^{* \star *}$ & 0.0008 & $3.55(2.15-5.94)$ & $1.187^{+*}$ & 0.09 & $3.28(1.37-8.25)$ \\
\hline
\end{tabular}

The dependent variable is an indicator variable, yes/no polyps, measured on a two point scale $(1,0)$. In the reference groups are female, no smoking, no statin use, no history of diabetes mellitus and no family history of colon cancer, no aspirin use, and $\mathrm{CHC}$ negative. Significance levels are denoted as: ${ }^{*} 0.05<\mathrm{p}<0.10$, ${ }^{* *} 0.01<\mathrm{p}<0.05$, ${ }^{* * *} \mathrm{p}<0.01$.

colorectal cancer. It could also be that lifestyle factors including diet, exercise and cigarette use make associations with colorectal cancer challenging. The association of tobacco consumption and CRC is related to cigarettes per day, longer years of smoking, or larger pack years [21].

It is important to identify $\mathrm{CHC}$ as a risk factor for colonic adenomas to ensure this high-risk population gets the appropriate level of screening. CHC patients are much more likely to abuse intravenous drugs and to have a lower socioeconomic status [22]. This can be a significant barrier for colorectal cancer screening in these patients. Research has shown that $\mathrm{CHC}$ patients are actually less likely to undergo screening colonoscopies compared to the nonhepatitis population $[23,24]$. Limitations to this study involve analysis of patients in a single community practice with a retrospective design. The known confounding variables discussed above were accounted for, but there may be some unknown variables yet to be discovered. This study did not analyze the location of neoplasia within the colon or determine the presence of serrated sessile adenomas. This study also did not investigate the effect of $\mathrm{CHC}$ on hyperplastic polyps, only adenomatous polyps. Due to hyperplastic polyps being insignificant clinically, we did not include them in this study. Other factors that may have impacted the power of the statistical tests included the small number of observations per variable in the model, at surveillance. This resulted in the loss of association between increased neoplastic risk and male sex. The detection of other known risk factors such as obesity may have been impacted by a significantly larger proportion of obese patients in the control group $(49.7 \% v s .36 .8 \%$, p-value $<0.05)$. Overall, small sample sizes at screening and surveillance obviously reduces the power of the statistical tests.

While viral loads were available for patients with $\mathrm{HCV}$, different assays for determination of HCV RNA viral load precludes correlations between the level of viremia, number, and size of adenomas. This study indicates that $\mathrm{CHC}$ is an independent risk factor for colorectal neoplasia, specifically adenomas, increasing a patient's odds of having an adenomatous polyp by $255 \%$. CHC also appears to be a risk factor for increased numbers of colorectal adenomas in surveillance colonoscopies, increasing odds by $227 \%$. There appears to be a trend toward more adenomas and advanced neoplasia in $\mathrm{CHC}$ patients. Further research is warranted to determine if $\mathrm{CHC}$ patients require earlier colorectal cancer screening, shorter intervals of surveillance, and if $\mathrm{CHC}$ leads to a higher incidence of colorectal cancer.

\section{References}

1. Edlin BR, Eckhardt BJ, Shu MA, Holmberg SD, Swan T. Toward a more accurate estimate of the prevalence of hepatitis $C$ in the United States. Hepatology. 2015: 62: 1353-1363.

2. Corinna Dan RN. Viral Hepatitis Policy Advisor, Office of HIVIAIDS and Infectious Disease Policy, US. Department of Health and Human Services HCV 2 New CDC Resources: HIV \& HCV Outbreak Detection and Response. 2018.

3. Swart A, Burns L, Mao L, Grulich AE, Amin J, O'Connell DL, et al. The importance of blood-borne viruses in elevated cancer risk among opioiddependent people: a population-based cohort study. BMJ Open. 2016; 2.

4. Chen C-J, Hsu W-L, Yang H-I, Lee M-H, Chen H-C, Chien Y-C, et al. Epidemiology of virus infection and human cancer. Recent Results Cancer Res. 2014; 193: 11-32.

5. Fiorino S, Bacchi-Reggiani L, Pontoriero L, Gallo C, Chilli E, Masetti M, et al. Pancreatic carcinoma development: new etiological and pathogenetic evidence. Italian J Med. 2013; 7: 242-252.

6. Fiorino S, Bacchi-Reggiani L, Biase D, Fornelli A, Masetti M, Tura A, et al. Possible association between hepatitis $C$ virus and malignancies different from hepatocellular carcinoma: A systematic review. World Journal of Gastroenterology. 2015; 21: 12896-12953.

7. American Cancer Society. Cancer Facts and Figures 2018. Atlanta, Ga: American Cancer Society. 2018.

8. Issa IA, Noureddine M. Colorectal cancer screening: An updated review of the available options. World J Gastroenterol. 2017; 23: 5086-5096.

9. Doubeni CA, Weinmann S, Adams K, Kamineni A, Buist DSM, Ash AS, et al. Screening colonoscopy and risk for incident late-stage colorectal cancer diagnosis in average-risk adults: a nested case-control study Ann Intern Med. 2013; 158: 312-320.

10. Le Marchand L, Wilkens LR, Kolonel LN, Hankin JH, Lyu LC. Associations of sedentary lifestyle, obesity, smoking, alcohol use and diabetes with the risk of colorectal cancer. Cancer Res. 1997; 57: 4787-4794.

11. Botteri E, lodice S, Raimondi S, Maisonneuve P, Lowenfels AB. Cigarette smoking and adenomatous polyps: a meta-analysis. Gastroenterology. 2008; 134: 388-395.

12. Wei EK, Colditz GA, Giovannucci EL, Fuchs CS, Rosner BA. Cumulative risk of colon cancer up to age 70 years by risk factor status using data from the Nurses' Health Study. Am J Epidemiol. 2009; 170: 863-872.

13. Pelucchi C, Negri E, Talamini R, Levi F, Giacosa A, Crispo A, et al. Metabolic syndrome is associated with colorectal cancer in men. Eur J Cancer. 2010; 
46: $1866-1872$.

14. Cheskin LJ, Prosser BJ. Obesity and the risk of colon polyps. J Clin Gastroenterol. 2007; 41: 229-230.

15. Lasry A, Zinger A, Ben-Neriah Y. Inflammatory networks underlying colorectal cancer. Nat Immunol. 2016; 17: 230-240.

16. Hanahan D, Weinberg RA. Hallmarks of cancer: the next generation. Cell. 2011; 144: 646-674.

17. Erben V, Carr PR, Holleczek B, Stegmaier C, Hoffmeister M, Brenne $\mathrm{H}$. Strong associations of a healthy lifestyle with all stages of colorectal carcinogenesis: results from a large cohort of participants of screening colonoscopy. Int J Cancer. 2019.

18. Garcia-Albeniz X, Chan AT. Aspirin for the prevention of colorectal cancer Best Pract Res Clin Gastroenterol. 2011; 25: 461-472.

19. Lytras T, Nikolopoulos G, Bonovas S. Statins and the risk of colorectal cancer: an updated systematic review and meta-analysis of 40 studies. World J Gastroenterol. 2014; 20: 1858-1870.
20. Liu Y, Tang W, Wang J, Xie L, Li T, He Y, et al. Association between statin use and colorectal cancer risk: a meta-analysis of 42 studies. Cancer Causes Control. 2014; 25: 237-249.

21. Tsoi KKF, Pau CYY, Wu WKK, Wu Francis KL, Chan FKL, Griffiths S, et al. Cigarette Smoking and the Risk of Colorectal Cancer: A Meta-analysis of Prospective Cohort Studies. Clinical Gastroenterology and Hepatology. 2009.

22. Zickmund S, Hillis SL, Barnett MJ, Ippolito L, LaBrecque DR. Hepatitis C virus-infected patients report communication problems with physicians. Hepatology. 2004; 39: 999-1007.

23. Rustagi TDK, Diez F. Screening colonoscopy in chronic hepatitis $C$ patients. Am J Gastroenterol. 2010; 105: A1511.

24. Prakash RSN, Putka B, Mullen K. Superior colorectal cancer screening in hepatitis C population. Am J Gastroentero. 2009; 104: S420-S421. 